\title{
Comparison of birthweight and infant mortality between Singapore and England and Wales, 1980
}

\author{
KENNETH HUGHES
}

From the Department of Social Medicine and Public Health, National University of Singapore, Outram Hill, Singapore 0316

SUMMARY For 1980 Singapore was found to have overall a more favourable birthweight distribution than England and Wales. The proportion of very low birthweight babies (less than $1500 \mathrm{~g}$ ) and heavy babies (3500 $\mathrm{g}$ and over) was $0.4 \%$ and $18 \cdot 5 \%$ in Singapore and $0.7 \%$ and $34.9 \%$ in England and Wales for live births, and $0.6 \%$ and $18.5 \%$ against $0.9 \%$ and $34 \cdot 7 \%$ for total births. However, for low birthweight (less than $2500 \mathrm{~g}$ ) Singapore with $7 \cdot 5 \%$ in live births and $7 \cdot 9 \%$ in total births had higher rates than England and Wales (6.7\% and $7 \cdot 2 \%)$. While infant mortality rates were very similar, Singapore had a somewhat higher neonatal mortality rate but a considerably lower postneonatal mortality rate than England and Wales. The effects on mortality of standardising for birthweight are examined. The problems of interpretation and the implications of the findings are discussed.

Birthweight is a reflection of maternal health and as such is an indicator of the health status of a population. Also an infant's chance of surviving the perinatal period is to a large extent dependent on its weight at birth. Indeed the birthweight distribution has been considered as an index of perinatal health. ${ }^{1}$

In many countries, especially developing ones, birthweight is not recorded on the birth certificate, so that most studies on birthweight relate to births in health institutions with the consequent selective bias. The existing shortage of adequate data on birthweight, especially in the developing world, has been stressed. ${ }^{2}$

Singapore is an island state of about 2.3 million people with an ethnic composition of Chinese $(76 \cdot 9 \%)$, Malays $(14.6 \%)$, Indians $(6 \cdot 4 \%)$, and others $(2 \cdot 1 \%)$. The country has undergone rapid development over the last few decades, and the population now has total health care coverage. A study on the trends in birthweight of live singletons from 1967 to 1974 has been done on a random sample of births. ${ }^{3}$ However, in the last few years, birthweight in grams and basic demographic information have been recorded centrally on all births in Singapore. Likewise, data on birthweight have recently been collected centrally in England and Wales. It has been pointed out that low weight births are relatively uncommon in some Chinese populations and that this deserves closer investigation. ${ }^{4}$

This study is therefore a comparison of the birthweight distributions and also of perinatal and infant mortality rates, between Singapore and England and Wales for the year 1980. The World Health Organization (WHO) carried out in 1973 a detailed study on perinatal mortality and birthweight distribution in eight countries, thus illustrating the importance of international comparisons. ${ }^{5}$ It is to be noted that the data in both countries of this study relate to all births and are not samples.

\section{Materials and methods}

SOURCES

Data on birthweights and infant mortality rates for Singapore were obtained from the Department of Statistics. ${ }^{6}$ Births must by law be registered, and the registration of births is believed to be virtually complete as the birth certificate is an important document for a number of administrative purposes. The completeness of death registration is ensured by the legal requirement that a death has to be reported before a burial or a cremation permit can be obtained, and this applies also to stillbirths. Birth 
report forms including stillbirths record birthweight in grams together with demographic and biological data.

For England and Wales the data were obtained from OPCS Monitors for $1980 .{ }^{78}$ Birthweight is not a legal requirement in England and Wales but is notified. The transfer from notification to registration started in 1976 and by 1980 had improved to almost $87 \%$ of births.

In both Singapore and England and Wales the following definitions apply:

1 Birthweight distributions of live and still births are according to the Ninth Revision of International Classification of Diseases (ICD9), which was implemented in 1979. This defines low birthweight as less than $2500 \mathrm{~g}$, and birthweight grouping in the form under $1000 \mathrm{~g}$, $1000 \mathrm{~g}$ or over but less than $1500 \mathrm{~g}$, and so on.

2 A live birth is according to the WHO definition. ${ }^{9}$

3 A stillbirth is a fetal death after 28 completed weeks of gestation. Stillbirth rate is stillbirths per 1000 live and still births.

4 Perinatal mortality rate is stillbirths and deaths in the first week of life per 1000 live and still births.

5 Early neonatal mortality rate is deaths in the first 7 days of life per 1000 live births.

6 Neonatal mortality rate is deaths in the first 28 days of life per 1000 live births.

7 Postneonatal mortality rate is deaths at ages over 28 days and under 1 year per 1000 live births.

8 Infant mortality rate is deaths at ages under 1 year per 1000 live births.

\section{ANALYSIS}

The data analysed are for all births, single and multiple, and include examination by maternal age which is known to affect birthweight. ${ }^{5}$ It is not possible to compare data by gestational age as this is not collected for live births in England and Wales though it is in Singapore.

In Singapore, birth order refers to the numerical order of the child in relation to all previous live born issues of the mother, whereas in England and Wales parity is used and defined as the number of previous live or still born children. Also in Singapore birth order refers to all births whereas in England and Wales it is available only for women having a legitimate birth. Hence while birth order does affect birth weight, ${ }^{5}$ it is not possible to include this in the comparative analysis.

Likewise in Singapore classification of occupation conforms basically to the International Standard
Occupational Classification of the International Labour Office (seven major groups with one residual and three supplementary major categories), whereas in England and Wales it is five categories using the Classification of Occupations (1980 HMSO). Also occupational groupings in the two countries may well not be a good comparison of socioeconomic status. Hence again while social class does affect birth weight $^{3}$ it is not included in the analysis.

Standardisation is used in the comparison of $\Rightarrow$ perinatal and infant mortality rates to take birthweight into account, the aim being to separate the effect of a difference in birthweight from other effects on mortality. It has been said that standardisation is not wholly satisfactory for $\&$ birthweight distribution, ${ }^{10}$ but given that birthweight in specific mortality rates are not available for Singapore it is the only technique available and in fact is widely used. Indeed as many variables influence perinatal mortality through birthweight it has been suggested that standardisation removes the influence of "socioeconomic or demographic circumstances" on perinatal mortality and thus clarifies the effect of medical care. ${ }^{11}$ However the 1973 WHO study ${ }^{9}$ dis show that factors like maternal age, parity, birt $\vec{\omega}$ interval, and socioeconomic status do have som $\vec{\Phi}$ effect on perinatal mortality other than throug birthweight. Hence differences that remain if $c$ perinatal and infant mortality after standardising foథ birthweight are to a large extent but not completely result of medical care.

The standardised rates were obtained by direct standardisation, by applying the birthweight specific rates in England and Wales to the birthweight distribution in Singapore. Of course for stillbirth and perinatal mortality rates total births (live and still) have been used, whereas for early neonatal, neonatal, postneonatal, and infant mortality rates live births have been used.

For 1980 in Singapore there were a total of 41217 live births with $40898(99 \cdot 2 \%)$ stated birth weights, and in Engalnd and Wales 656234 live births with $569316(86.7 \%)$ stated birth weights. Likewise the numbers for stillbirths were $263(245$ or $93.2 \%$ stated) and 4773 (4046 or $84.8 \%$ stated) respectively. The births with stated birth weights are used in the analysis and, of the live births, multiple births accounted for $1.2 \%$ in Singapore and $1.9 \%$ in England and Wales.

Information on infant and perinatal mortality by birthweight in England and Wales was achieved by $N$ linking the infant death record to the corresponding birth record. The overall infant and perinatal 0 mortality rates are slightly different from those in $\omega$ other publications as cases where either linkage 
failed or the birth record did not contain the birthweight were excluded.

\section{Results}

Table 1 shows the distribution of births by birthweight in 1980 . It can be seen that for live births Singapore has a smaller proportion of weights at the two extremes. The proportion of very low birthweight babies (less than $1500 \mathrm{~g}$ ) is $0.4 \%$ in Singapore and $0.7 \%$ in England and Wales. However, the percentage of babies weighing less than $2500 \mathrm{~g}$ but $2000 \mathrm{~g}$ or over is higher in Singapore $(6.0 \%$ against $4.8 \%)$ so that the incidence of low birthweight (less than $2500 \mathrm{~g}$ ) is higher in Singapore than in England and Wales $(7 \cdot 5 \%$ to $6 \cdot 7 \%)$. The proportion of births weighing $3500 \mathrm{~g}$ and over and $4000 \mathrm{~g}$ and over are higher in England and Wales $(34.9 \%$ and $8 \cdot 1 \%$ against $18 \cdot 5 \%$ and $2 \cdot 5 \%)$.

Table 1 also shows stillbirths by weight. Again the proportion of very low weight babies (less than
$1500 \mathrm{~g}$ ) is higher in England and Wales (33.3\% against $27 \cdot 4 \%$ ), but here the proportions below $2500 \mathrm{~g}$ are little different being $66.0 \%$ in England and Wales and $66.9 \%$ in Singapore. For total births (live and still) the same differences are found, Singapore having the smaller proportion of very low birthweights $(0.6 \%$ to $0.9 \%)$ and the higher proportion of low birthweights $(7 \cdot 9 \%$ to $7 \cdot 2 \%)$.

Table 2 shows the differing distributions of live births by age of mother. For very low birthweight babies the rates are higher in young (under 20 years) and older ( 35 years and over) women with no change in between, in both countries. The rates are consistently lower in Singapore except in the under 20 age group where the rates are the same. In both countries the percentage of low birthweight babies falls with increasing maternal age and then at 35 years and over rises again but is still well below the levels for teenage mothers $(12.9 \%$ in Singapore and 9.3\% in England and Wales). At all ages Singapore rates are higher than for England and Wales. For the

Table 1 Live births and stillbirths by birthweight

\begin{tabular}{|c|c|c|c|c|c|c|}
\hline \multirow[b]{2}{*}{$\begin{array}{l}\text { Birthweight } \\
\text { (g) }\end{array}$} & \multicolumn{2}{|l|}{ Live births } & \multicolumn{2}{|l|}{ Stillbirths } & \multicolumn{2}{|l|}{ All births } \\
\hline & $\begin{array}{l}\text { Singapore } \\
\left(\%_{1}\right)\end{array}$ & $\begin{array}{l}\text { England } \\
\text { \& Wales } \\
\left(x_{1}\right)\end{array}$ & $\begin{array}{l}\text { Singapore } \\
(\%)\end{array}$ & $\begin{array}{l}\text { England } \\
\& \text { Wales } \\
(\%)\end{array}$ & $\begin{array}{l}\text { Singapore } \\
(\%)\end{array}$ & $\begin{array}{l}\text { England } \\
\text { \& Wales } \\
(\%)\end{array}$ \\
\hline Under 1500 & 0.4 & 0.7 & $27 \cdot 4$ & 33.3 & 0.6 & 0.9 \\
\hline Under 2500 & $7 \cdot 5$ & $6 \cdot 7$ & 66.9 & $66 \cdot 0$ & 7.9 & $7 \cdot 2$ \\
\hline Under 1000 & $0 \cdot 1$ & $0 \cdot 2$ & $15 \cdot 5$ & 13.9 & 0.2 & 0.3 \\
\hline $1000-1499$ & 0.3 & 0.5 & 13.9 & $19 \cdot 4$ & 0.4 & 0.6 \\
\hline $1500-1999$ & $1 \cdot 1$ & $1 \cdot 3$ & $20 \cdot 0$ & $17 \cdot 3$ & $1 \cdot 2$ & $1 \cdot 4$ \\
\hline $2000-2499$ & 6.0 & $4 \cdot 8$ & $17 \cdot 6$ & $15 \cdot 4$ & $6 \cdot 1$ & $4 \cdot 8$ \\
\hline $2500-2999$ & $29 \cdot 8$ & $19 \cdot 2$ & $13 \cdot 5$ & $14 \cdot 8$ & $29 \cdot 7$ & $19 \cdot 2$ \\
\hline $3000-3499$ & $44 \cdot 1$ & $39 \cdot 1$ & $10 \cdot 2$ & 11.0 & 43.9 & 38.9 \\
\hline 3500-3999 & $16 \cdot 0$ & $26 \cdot 8$ & $8 \cdot 2$ & $5 \cdot 5$ & $16 \cdot 0$ & $26 \cdot 7$ \\
\hline 4000 and over & $2 \cdot 5$ & $8 \cdot 1$ & $1 \cdot 2$ & $2 \cdot 7$ & $2 \cdot 5$ & 8.0 \\
\hline
\end{tabular}

Table 2 Live births by birthweight and mother's age

\begin{tabular}{|c|c|c|c|c|c|c|c|c|c|c|c|}
\hline \multirow[b]{2}{*}{$\begin{array}{l}\text { Age of } \\
\text { mother }\end{array}$} & \multirow[b]{2}{*}{$\begin{array}{l}\text { Distribution } \\
(\%)\end{array}$} & \multicolumn{10}{|c|}{$\begin{array}{l}\text { Birthweight (g) } \\
\left(\Psi_{1}\right)\end{array}$} \\
\hline & & $\begin{array}{l}\text { Under } \\
1500\end{array}$ & $\begin{array}{l}\text { Under } \\
2500\end{array}$ & $\begin{array}{l}\text { Under } \\
1000\end{array}$ & $\begin{array}{l}1000 \\
1499\end{array}$ & $\begin{array}{l}1500 \\
1999\end{array}$ & $\begin{array}{l}2000 \\
2499\end{array}$ & $\begin{array}{l}2500 \\
2999\end{array}$ & $\begin{array}{l}3000 \\
3499\end{array}$ & $\begin{array}{l}3500 \\
3999\end{array}$ & $\begin{array}{l}4000 \\
\text { and over }\end{array}$ \\
\hline \multicolumn{12}{|l|}{ Singapore } \\
\hline Under 20 & $4 \cdot 2$ & $1 \cdot 1$ & $12 \cdot 9$ & 0.2 & 0.9 & $2 \cdot 2$ & 9.7 & $37 \cdot 0$ & $39 \cdot 1$ & $10 \cdot 1$ & 0.8 \\
\hline $20-24$ & $27 \cdot 8$ & 0.4 & $8 \cdot 3$ & 0.1 & 0.3 & $1 \cdot 1$ & $6 \cdot 8$ & $32 \cdot 5$ & $44 \cdot 0$ & $13 \cdot 5$ & 1.8 \\
\hline $25-29$ & $41 \cdot 4$ & 0.4 & 6.9 & $0 \cdot 1$ & 0.3 & 1.0 & $5 \cdot 5$ & $28 \cdot 7$ & $45 \cdot 1$ & 16.6 & $2 \cdot 7$ \\
\hline $30-34$ & $21 \cdot 3$ & 0.4 & 6.6 & $0 \cdot 1$ & 0.3 & 0.9 & $5 \cdot 2$ & $27 \cdot 4$ & $44 \cdot 5$ & $18 \cdot 4$ & $3 \cdot 1$ \\
\hline $35 \&$ over & 5.4 & 0.6 & $8 \cdot 6$ & $0 \cdot 1$ & 0.5 & $1 \cdot 1$ & $6 \cdot 8$ & $27 \cdot 9$ & 39.4 & $19 \cdot 3$ & $4 \cdot 8$ \\
\hline \multicolumn{12}{|c|}{ England \& Wales } \\
\hline Under 20 & 9.5 & $1 \cdot 1$ & $9 \cdot 3$ & 0.3 & 0.8 & 1.8 & $6 \cdot 5$ & $23 \cdot 4$ & $39 \cdot 9$ & $22 \cdot 1$ & $5 \cdot 2$ \\
\hline $20-24$ & $30 \cdot 8$ & 0.7 & $7 \cdot 2$ & 0.2 & $0 \cdot 5$ & $1 \cdot 3$ & $5 \cdot 2$ & $21 \cdot 5$ & $40 \cdot 0$ & $24 \cdot 8$ & 6.6 \\
\hline $25-29$ & $33 \cdot 8$ & 0.6 & $6 \cdot 0$ & 0.2 & 0.5 & $1 \cdot 1$ & $4 \cdot 3$ & $18 \cdot 2$ & 39.4 & 28.0 & 8.4 \\
\hline $30-34$ & $19 \cdot 8$ & 0.6 & $5 \cdot 7$ & 0.2 & 0.5 & $1 \cdot 1$ & $4 \cdot 0$ & $16 \cdot 3$ & $37 \cdot 7$ & 29.0 & $10 \cdot 5$ \\
\hline $35 \&$ over & $6 \cdot 3$ & 0.8 & $7 \cdot 3$ & 0.2 & 0.6 & 1.5 & $5 \cdot 1$ & $17 \cdot 2$ & 36.6 & $28 \cdot 3$ & 10.6 \\
\hline
\end{tabular}


heavier babies ( $4000 \mathrm{~g}$ and over) the proportion rises with maternal age in both countries, with lower rates in Singapore at all ages: $4.8 \%$ of babies born to mothers aged 35 or older compared to only $0.8 \%$ of babies born to teenage mothers in Singapore, with proportions of $10.6 \%$ and $5 \cdot 2 \%$ in England and Wales.

Stillbirths by age of mother are shown in Table 3. The percentage of very low birthweight babies decreases with maternal age in both countries, being lower in Singapore at all ages. For low birthweight babies the proportion falls with maternal age in England and Wales but there is no real consistent trend in Singapore. The percentage of babies weighing $3500 \mathrm{~g}$ or over increases with maternal age in both countries and is lower in Singapore in the younger ages but then higher in older women. Tables 2 and 3 also show that Singapore has a much lower proportion of teenage mothers; in particular for live births this is less than half $(4 \cdot 2 \%$ against $9 \cdot 5 \%)$.

Table 4 shows perinatal and infant mortality rates in Singapore and England and Wales, both crude and standardised for birthweight. It can be seen that standardisation for birthweight reduces perinatal, early neonatal, and neonatal mortality rates in England and Wales due to the smaller proportion of very low and high birthweight babies in Singapore. However standardisation increases the postneonatal mortality rate due to the fact, as shown in rates for England and Wales, that very low birthweight does not have such a marked effect on postneonatal mortality (if a very low birthweight baby is going to die then it usually dies early), and also while for very heavy babies ( $4000 \mathrm{~g}$ and over) the neonatal rates increase, the postneonatal mortality rate continues to decline.

As can be seen in Table 4 the stillbirth rate is slightly higher in England and Wales, though it is somewhat reduced by standardising for birthweight. Perinatal, early neonatal, and neonatal mortality कै rates are conversely slightly higher in Singapore, and the difference is increased by standardisation. Postneonatal mortality rate, however, is much higher in England and Wales and after standardising is $42 \%$ higher than in Singapore (4.8 against 2.8 per 1000 live births). Finally, infant mortality rate is more or less the same in the two countries and is little affected by standardising for birthweight.

Table 3 Stillbirths by birthweight and mother's age

\begin{tabular}{|c|c|c|c|c|c|c|c|c|c|c|c|}
\hline \multirow[b]{2}{*}{$\begin{array}{l}\text { Age of } \\
\text { mother }\end{array}$} & \multirow[b]{2}{*}{$\begin{array}{l}\text { Distribution } \\
(\%)\end{array}$} & \multicolumn{10}{|c|}{$\begin{array}{l}\text { Birthweight }(g) \\
(\%)\end{array}$} \\
\hline & & $\begin{array}{l}\text { Under } \\
1500\end{array}$ & $\begin{array}{l}\text { Under } \\
2500\end{array}$ & $\begin{array}{l}\text { Under } \\
1000\end{array}$ & $\begin{array}{l}1000 \\
1499\end{array}$ & $\begin{array}{l}1500- \\
1999\end{array}$ & $\begin{array}{l}2000 \\
2499\end{array}$ & $\begin{array}{l}2500- \\
2999\end{array}$ & $\begin{array}{l}3000 \\
3499\end{array}$ & $\begin{array}{l}3500 \\
3999\end{array}$ & $\begin{array}{l}4000 \\
\text { and over }\end{array}$ \\
\hline \multicolumn{12}{|l|}{ Singapore } \\
\hline Under 20 & $6 \cdot 3$ & $40 \cdot 0$ & $66 \cdot 7$ & $26 \cdot 7$ & $13 \cdot 3$ & $26 \cdot 7$ & - & $26 \cdot 7$ & $6 \cdot 7$ & - & - \\
\hline $20-24$ & $24 \cdot 7$ & $32 \cdot 8$ & $63 \cdot 8$ & $17 \cdot 2$ & $15 \cdot 5$ & $19 \cdot 0$ & $12 \cdot 1$ & $20 \cdot 7$ & $10 \cdot 3$ & 3.4 & $1 \cdot 7$ \\
\hline $25-29$ & $35 \cdot 1$ & $31 \cdot 0$ & $73 \cdot 8$ & $19 \cdot 0$ & 11.9 & $16 \cdot 7$ & $26 \cdot 2$ & $10 \cdot 7$ & $8 \cdot 3$ & $6 \cdot 0$ & $1 \cdot 2$ \\
\hline $30-34$ & $21 \cdot 8$ & $28 \cdot 8$ & $69 \cdot 2$ & $7 \cdot 7$ & $21 \cdot 2$ & $21 \cdot 2$ & 19.9 & $7 \cdot 7$ & $7 \cdot 7$ & $15 \cdot 4$ & - \\
\hline 35 \& over & $12 \cdot 1$ & 20.7 & 55.2 & $13 \cdot 8$ & 6.9 & 20.7 & $13 \cdot 8$ & 6.9 & $17 \cdot 2$ & $17 \cdot 2$ & 3.4 \\
\hline \multicolumn{12}{|c|}{ England \& Wales } \\
\hline Under 20 & 10.6 & $41 \cdot 7$ & $73 \cdot 2$ & 16.6 & $25 \cdot 2$ & 18.9 & $12 \cdot 6$ & $11 \cdot 7$ & 8.9 & $4 \cdot 7$ & $1 \cdot 6$ \\
\hline $20-24$ & 29.5 & 33.9 & $68 \cdot 6$ & $14 \cdot 1$ & 19.9 & 18.7 & $15 \cdot 9$ & $13 \cdot 7$ & $10 \cdot 2$ & $5 \cdot 5$ & $2 \cdot 1$ \\
\hline $25-29$ & $30 \cdot 5$ & 32.9 & $64 \cdot 3$ & $14 \cdot 4$ & $18 \cdot 5$ & $17 \cdot 3$ & $14 \cdot 1$ & 16.6 & $11 \cdot 7$ & $4 \cdot 7$ & $2 \cdot 7$ \\
\hline $30-34$ & $19 \cdot 5$ & $30 \cdot 5$ & 63.6 & 11.4 & $19 \cdot 0$ & 15.9 & $17 \cdot 3$ & 15.5 & $10 \cdot 8$ & $6 \cdot 3$ & $3 \cdot 8$ \\
\hline $35 \&$ over & 10.0 & $28 \cdot 8$ & 60.5 & 13.4 & 15.4 & $14 \cdot 6$ & $17 \cdot 1$ & $14 \cdot 4$ & $14 \cdot 1$ & $7 \cdot 4$ & $3 \cdot 5$ \\
\hline
\end{tabular}

Table 4 Infant mortality rates crude and standardised for birthweight distribution

\begin{tabular}{|c|c|c|c|c|c|c|c|c|c|c|c|c|}
\hline \multirow[b]{3}{*}{ Country } & \multirow{2}{*}{\multicolumn{2}{|c|}{ Stillbirth rate }} & \multicolumn{10}{|c|}{ Mortality rate } \\
\hline & & & \multicolumn{2}{|c|}{ Perinatal } & \multicolumn{2}{|c|}{ Early neonatal } & \multicolumn{2}{|c|}{ Neonatal } & \multicolumn{2}{|c|}{ Postneonatal } & \multicolumn{2}{|l|}{ Infant } \\
\hline & Crude & Standardised ${ }^{*}$ & Crude & Standardised ${ }^{*}$ & Crude & Standardised ${ }^{*}$ & Crude & Standardised ${ }^{*}$ & Crude & Standardised $^{*}$ & Crude & Standardised ${ }^{*}$ \\
\hline $\begin{array}{l}\text { Singapore } \\
\text { England and Wales }\end{array}$ & $\begin{array}{r}6.4 \\
6.9\end{array}$ & $\begin{array}{l}6 \cdot 4 \\
6 \cdot 6\end{array}$ & $\begin{array}{l}13 \cdot 4 \\
12 \cdot 6\end{array}$ & $\begin{array}{l}13 \cdot 4 \\
11 \cdot 7\end{array}$ & $\begin{array}{l}7 \cdot 1 \\
5 \cdot 8\end{array}$ & $\begin{array}{l}7 \cdot 1 \\
5 \cdot 0\end{array}$ & $\begin{array}{l}8 \cdot 9 \\
7 \cdot 2\end{array}$ & $\begin{array}{l}8 \cdot 9 \\
6 \cdot 4\end{array}$ & $\begin{array}{l}2 \cdot 8 \\
4 \cdot 2\end{array}$ & $\begin{array}{l}2 \cdot 8 \\
4 \cdot 8\end{array}$ & $\begin{array}{l}11 \cdot 7 \\
11 \cdot 4\end{array}$ & $\begin{array}{l}11 \cdot 7 \\
11 \cdot 0\end{array}$ \\
\hline
\end{tabular}

"Rates obtained by direct standardisation using the distribution of births by birthweight in Singapore as the standard distribution. 


\section{Discussion}

A problem in international comparisons of birthweight and perinatal mortality is that while the definition of a stillbirth and a live birth may be uniform, particular differences in the way these definitions are applied can cause problems. Thus the same baby might be reported in one population as being born alive and dying immediately after birth and hence a live birth and neonatal death, and yet recorded in another population as a late fetal death or abortion (if before 28 weeks) and so not included in live births. The practice of classifying these live births as stillbirths or abortions will tend to differentially remove smaller babies, which are more likely to die immediately after birth, from the live birth statistics, and so give the impression of a lower proportion of very low birthweight babies. Also it will reduce early neonatal and neonatal mortality and increase late fetal mortality.

The question is whether this can have happened to a significant degree in Singapore compared to England and Wales. A way to look at this is to calculate the proportion of early neonatal deaths within total perinatal mortality as misclassification will reduce this. The proportions come out as England and Wales $45.4 \%$ and Singapore $52.5 \%$. Hence there is no evidence here that Singapore is misclassifying live births as stillbirths, at least in relation to England and Wales. However of course any misclassification between stillbirths and live births is taken care of by looking at total births and perinatal mortality.

What then can be said of Singapore relative to England and Wales in relation to birthweight distribution? Singapore does have the more favourable birthweight distribution of live births with smaller proportions of both very low (less than $1500 \mathrm{~g}$ ) and high (3000 g and over) birthweight groups (Table 1). Perhaps more importantly, Table 1 shows that the incidence of very low birthweight among total births (still and live) is similarly lower in Singapore (0.6\%) than in England and Wales (0.9\%), and the lower rates hold for virtually all maternal age groups (Tables 2 and 3 ). The more favourable overall birthweight distribution in Singapore is further shown by the fact that perinatal and neonatal mortality rates for England and Wales fall on standardising to the Singapore birthweight distribution (Table 4).

However it is low birthweight with a cut off point of $2500 \mathrm{~g}$ that is universally adopted, and for this the incidence is higher in Singapore than in England and Wales, though this is due entirely to the higher proportion in the $2000-2499 \mathrm{~g}$ range (Table 1). This illustrates the limitations of this international standard of less than $2500 \mathrm{~g}$, for it would incorrectly indicate Singapore as having the less favourable birthweight distribution.

What then are the possible reasons for the more favourable birthweight distribution in Singapore with, in particular, a lower incidence of very low birthweight babies? The proportion of multiple births is lower in Singapore (1.2\%) than in England and Wales $(1.9 \%)$. Also the proportion of teenage pregnancies is lower in Singapore (4.2\% against 9.5\% for all births), though the lower proportion of very low birthweight babies runs in all age groups (Tables 2 and 3). Illegitimacy likewise is uncommon in Singapore. Maternal and child health clinics cover the island, ensuring continuing primary health care to virtually all pregnant women, though it has to be said that the effect of medical care on birthweight is equivocal at best. Smoking, which in pregnancy is established as a cause of low birthweight, ${ }^{12}$ was found in a survey in Singapore in $1975^{13}$ to be uncommon in adult women.

However the possibility remains that genetic influences may be important. The majority of births in Singapore are Chinese $(74.0 \%)$. There is no information on the ethnicity of births in England and Wales, and while of course Indian and West Indian births are increasingly significant, the majority are still 'white Caucasian'. These data do seem to agree with the observations that very low birthweight is relatively less common in Chinese. ${ }^{4}$ Indeed, there is evidence that the pattern of fetal growth in Chinese populations differs from that in Caucasian groups with early fetal growth seemingly more rapid. ${ }^{14}$

As Tables 2 and 3 show, the birthweight pattern of both live and stillborn babies by age of mother is very similar in the two countries. The higher frequency of low birthweight for both younger and older mothers has been established, although in the WHO international study in $1973^{5}$ it was found that in the seven countries (Austria, Cuba, Hungary, Japan, New Zealand, Sweden, and USA) the lowest rate for live births tended to be in the 25-29 age group rather than in the 30-34 age group found here in both Singapore and England and Wales. It should be noted that England and Wales was the eighth country in this study but was excluded from the birthweight comparisons as information on birthweight was not then available.

Perinatal and infant mortality rates by birthweight and mother's age are available for England and Wales, hence these rates can be standardised for both variables to the Singapore distribution. It is found that perinatal mortality rate in England and Wales standardised for both birthweight and maternal age is 11.9 while the infant mortality rate is 10.7 , both values being little different from the rates 
standardised only for birthweight (Table 4). Given that the distributions of births by maternal age are different in the two countries (Tables 2 and 3), this shows how maternal age here affects mortality largely though not completely through effects on birthweight, as discussed above.

Crude infant mortality rate and especially neonatal mortality rate is dependent on both the birthweight specific mortality and the birthweight distribution. It would have been preferable to compare directly birthweight specific mortality but as there is no birth-death information linkage in Singapore, this was not possible. As Table 4 shows, infant mortality rates are more or less the same as also are stillbirth rates. For perinatal, early neonatal and neonatal mortality, England and Wales does have slightly lower rates and more so on standardising (adjusting) for birthweight. Hence overall England and Wales does have somewhat lower birthweight specific rates though it is not possible to say for which birthweight categories. With more intensive care of the newborn in the 1970s in England and Wales, a steady and increased rate of fall in early deaths has been seen. ${ }^{13}$ Indeed the rate of decline in perinatal mortality over the years 1973 to 1978 was far greater at $26 \%$ than that in any similar period since stillbirth registration began in $1931,{ }^{16}$ yet in 1980 Singapore was only just behind and had experienced a similar decline of $24 \%$ from 20.0 in 1973 to 15.2 in 1978 . This decline in perinatal mortality in Singapore has occurred with greater provision of neonatal facilities in hospitals, legalised abortion since 1969 , and effective family planning, resulting in a two child family in most cases.

With regard to postneonatal mortality Singapore is in a much better position. Perhaps to some extent of course lives saved in the neonatal period are then lost in the postneonatal period. However it has been pointed out that for postneonatal mortality England and Wales lags behind other European countries. ${ }^{17}$ Many of the factors implicated in postneonatal deaths are "social" rather than "medical", and Singapore now enjoys very high standards of environmental conditions with piped water and sewage disposal available to virtually all homes. Also many postneonatal deaths happen out of hospitals and away from medical care and interventions, ${ }^{18}$ but this is less likely to happen in Singapore as it is a small island with no outlying rural areas so that medical care is quickly on hand.

In conclusion, it can be said that Singapore, a rapidly developing country, had by 1980 a birthweight distribution that on the whole was more favourable than that of England and Wales, perinatal and neonatal mortality rates only just higher, and a much lower postneonatal mortality rate.

I wish to thank Miss W Louis for typing the I manuscript.

\section{References}

${ }^{1}$ Chalmers I. The search for indices. Lancet 1979; ii: $\vec{\circ}$ 1063-5.

${ }^{2}$ World Health Organization. The incidence of low $\vec{\omega}$ birthweight a critical review of available information. $\frac{O}{0}$
World Health Stat $Q$ 1980; 33: 197-224.

${ }^{3}$ Hughes K, Tan NR, Lun KC. Low birthweight of live $\stackrel{\circ}{\rightarrow}$ singletons in Singapore 1967-1974. Int J. Epidemiol $\omega$ 1984; 13: 465-71.

${ }^{4}$ Chalmers I. Shanghai. Lancet 1980; i: 137-9.

World Health Organization. Social and biological effect $\omega$ on perinatal mortality: a WHO report volume 1. Saud o Medical Journal 1983; 4 supplement 1.

${ }^{6}$ Republic of Singapore. Report on Registration of Birt gif and Deaths 1980. Singapore: Eurasia Press.

${ }^{7}$ Office of Population Censuses and Surveys. Birthweig statistics 1980. OPCS Monitor 1981; DH3 81/4.

${ }^{8}$ Office of Population Censuses and Surveys. Infant an perinatal mortality by birthweight: 1980 estimates. OPब Monitor 1983; DH3 83/1.

${ }^{9}$ World Health Organization. Manual of the International Statistical Classification of Diseases, Injuries and Causes of Death. Ninth Revision 1975, Volume 1, Geneva.

${ }^{10}$ Wilcox AJ, Russell IT. Perinatal mortality: standardizing for birthweight is biased. Am J Epidemiol 1983; 118: $857-64$.

${ }^{11}$ Paneth $\mathrm{N}$. (Editorial). Infant mortality reexamined. JAMA 1982; 247: 1027-8.

${ }^{12}$ Herriot A, Billewicz WZ, Hytten FE. Cigarette smoking in pregnancy. Lancet 1962; 1: 771-3.

${ }^{13}$ Lee HP. Smoking and blood pressure among adults in Singapore. Ann Acad Med Singapore 1980; 9: 416-20.

${ }^{14} \mathrm{Lin}$ CC, Emanuel I. A comparison of American and Chinese intrauterine growth standards. Are American babies really smaller? Am J Epidemiol 1972; 95: ? 418-30.

${ }^{15}$ Pharoah POD, Alberman ED. Mortality of low birth weight infants in England and Wales 1953-1979. Arch $\dot{8}$ Dis Childh 1981; 56: 86-9.

${ }^{16}$ MacFarlane A. Perinatal mortality. Lancet 1979; ii: 255-6.

${ }^{17}$ Pharoah POD, Morris JN. Postneonatal mortality.

Epidemiol Rev 1979; 1: 170-83.
${ }^{18}$ Editorial. Comparisons of infant mortality. Lancet 1982; ii: $136-7$. 